\title{
Phytochemical Screening of Essential Oil of Citrus sinensis by Gas Chromatography-Flame Ionization Detector
}

\author{
Kammegne Djidjou Patricia ${ }^{1}$, Bella Oden Gervais Martial ${ }^{2}$ and Dongo Kenfack Kelack Justine Yvonne ${ }^{3}$ \\ 1. Laboratory of Biochemistry, University of Douala, Douala 2701, Cameroon \\ 2. Industrial Laboratory, GIC Bellomar Society, Douala 1010, Cameroon \\ 3. Research Unit in International Development, Dale Kietzman University of California, Douala 7006, Cameroon
}

\begin{abstract}
Citrus sinensis commonly called sweet orange belongs to the family Rutaceae. Nutritionally, it is highly recommended due to its high content of micronutrients. However, the rejection of a large amount of epicarp in nature contributes to the emission of greenhouse gas and the development of leachate which contaminate surface water and groundwater. The aim of this work was to identify the essential oil components from Citrus sinensis epicarp, and then look after the biological activity of these components in order to underline the worth to reuse the Citrus sinensis epicarp as a gainful mean. The essential oil of 4,000 g of Citrus sinensis epicarp was done through the water steam distillation and $0.0287 \mathrm{~g}$ of essential oil was obtained; so a yield of $0.0007 \%$. The essential oil was then submitted to gas chromatography-flame ionization detector (GC-FID). The result revealed that the essential oil was teemed with 28 volatile compounds, including terpene compounds (50\%), aldehydes (32\%) and alcohols (18\%) whose anti-inflammatory, anti-diabetic, larvicidal and antioxidant activities were underlined.
\end{abstract}

Key words: Environment, Citrus sinensis, essential oil.

\section{Introduction}

Citrus sinensis commonly called sweet orange belongs to the family Rutaceae. Morphologically, the epicarp is made up of oil glands, which contain essential oil and thus cause its characteristic odor.

Biochemically, it has a high content of micronutrients, especially ascorbic acid (80 mg/100 g), vitamin $\mathrm{P}, \mathrm{B} 1, \mathrm{~B} 9, \mathrm{E}$, provitamin A, calcium (40 $\mathrm{mg} / 100 \mathrm{~g}$ ) and pectins. Besides, it contributes to the regulation of intestinal transit, then their flora is rich of microorganisms, namely yeast and lactobacillus, essential for proper digestion [1]; this could justify the fact that it is nutritionally recommended. This results in an increased number of outlets in the city of Douala.

It is generally sold peeled throughout the year, and the finding of the rejection of a large amount of

Corresponding author: Kammegne Djidjou Patricia, Ph.D., research field: biochemistry. E-mail:kadjipa@yahoo.fr. epicarp in nature, particularly along the markets and along sidewalks, is obvious. Thus, this lucrative activity contributes on one hand to the urban unhealthy; on the other hand, the landfill biodegradation of these epicarps takes about two years and contributes to greenhouse gas emissions and the development of leachate contaminating surface water and groundwater [2].

Yet, these epicarps could be an important source of secondary metabolites. Indeed, numerous studies have attributed bioactive activities to volatile compounds of essential oils derived from citrus fruit epicarp. Indeed, anti-microbial activity of Citrus limellioides Tanaka was stressed [3].

In order to better manage organic waste in the city of Douala, the value of Citrus sinensis epicarp through the extraction of their essential oil was considered. Identification of volatile compounds of this essential oil is determined to support its bioactive nature and 
justify its use as a gainful mean. An investigation of the therapeutic properties of this essential oil had been conducted through a similar reasoning based on a comparison between the therapeutic properties already assigned to many volatile compounds and the compounds identified in the essential oil of interest.

\section{Materials and Methods}

\subsection{Plant Materials}

Fresh epicarps of Citrus sinensis were collected in January 2014 from vendors in four districts of the city of Douala-Bepanda, Deido, Central Market, Carrefour Elf. They were identified at the Cameroon Forestry Research Service and the voucher number was $25859 \mathrm{SRF} / \mathrm{Cam}$.

\subsection{Extraction of Essential Oil}

The extraction was carried out using a semi industrial steam distillation apparatus locally manufactured; it was made up of stripping vessel provided with an extraction basket, a tank provided with a cooling coil outlet and an improved furnace.

The distillation of 4,000 $\mathrm{g}$ epicarp was performed in four steps of $1,000 \mathrm{~g}$ each based on the principle of water steam distillation. Distillates obtained after each distillation were mixed. The resulting mixture was dried by anhydrous sodium sulfate and the essential oil was collected and stored at $4{ }^{\circ} \mathrm{C}$ in dark bottles.

\subsection{Analysis of Compounds by Gas Chromatography-Flame Ionization Detector (GC-FID)}

Chemical analysis of the essential oil obtained was performed using a chromatograph (HP 6850) through the injection of $0.2 \mu \mathrm{L}$ of a solution which is made up of essential oil and hexane. The carrier gas was helium at a flow rate of $0.7 \mathrm{~mL} / \mathrm{min}$. The column used is a capillary column DB-WAX $20 \mathrm{~m}$ in length and 0.1 $\mathrm{mm}$ in internal diameter. The thickness of stationary phase was $0.25 \mu \mathrm{m}$. The programming of oven temperature was $60{ }^{\circ} \mathrm{C}$ for $2 \mathrm{~min}$, and then it was in increments of $12{ }^{\circ} \mathrm{C} / \mathrm{min}$ to $248{ }^{\circ} \mathrm{C}$ in $5 \mathrm{~min}$. The detector used in this study was flame ionization detector (FID). All of that was controlled by a computer with National Institute of Standards and Technology (NIST) database which allowed the identification of compounds.

\subsection{Ethics}

This research had been done in an ethical manner. It did not harm people, to whom the epicarp of Citrus sinensis was gathered. Neither their privacy nor their health was exposed. They were mentioned anonymously. They were not robbed of their property, the epicarp of Citrus sinensis or orange peel was collected for the trash.

\section{Results}

The essential oil extracted has a clear appearance, orange yellow color (Fig. 1), with a characteristic odor of orange peel, sweet and fruity.

\subsection{Extraction Yield}

The extraction yield was estimated as a percentage of relative weight of the essential oil extracted from the peel weight. As shown in Table 1, the yield of the extraction was $0.0007 \%$; it is really low in comparison to initial epicarp weight collected.

\subsection{Chemical Composition of the Essential Oil of} Citrus sinensis

Analyses revealed that the essential oil of Citrus sinensis is teemed of 28 volatiles compounds. Fifty percent of them are terpene compounds, $18 \%$ are alcohol and $32 \%$ are formaldehyde. These compounds are listed in Table 2.

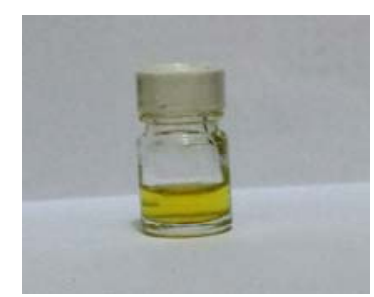

Fig. 1 Essential oil extracted. 
Table 1 Extraction yield.

\begin{tabular}{llll}
\hline Specie name & Epicarp weight $(\mathrm{g})$ & Essential oil weight $(\mathrm{g})$ & Yield (\%) \\
\hline Citrus sinensis & 4,000 & 0.0287 & 0.0007 \\
\hline
\end{tabular}

Table 2 Chemical composition of the essential oil of Citrus sinensis epicarp.

\begin{tabular}{|c|c|c|}
\hline Compounds & Content $(\%)$ & Retention time (min) \\
\hline$\alpha$ pinene & 0.53 & 2.478 \\
\hline$\beta$ pinene & Trace & 3.629 \\
\hline Sabinene & 0.33 & 3.989 \\
\hline$\delta$-3-carene & 0.05 & 4.131 \\
\hline Myrcene $+\alpha$ phellandrene & 1.92 & 4.022 \\
\hline Limonene & 94.40 & 4.850 \\
\hline$\beta$ phellandrene & 0.23 & 5.719 \\
\hline$\gamma$ terpinene & Trace & 6.959 \\
\hline Trans $\beta$ ocimene & Trace & 7.060 \\
\hline Terpinolene & Trace & 8.146 \\
\hline Octanal & 0.46 & 8.200 \\
\hline Nonanal & 0.08 & 8.583 \\
\hline$\delta$ elemene & 0.05 & 8.714 \\
\hline Citronellal & 0.05 & 9.268 \\
\hline Decanal & 0.38 & 10.031 \\
\hline Linalol & 0.45 & 10.123 \\
\hline$\beta$ caryophyllene & Trace & 10.311 \\
\hline Neral & 0.06 & 10.509 \\
\hline$\alpha$ terpineol & 0.03 & 10.346 \\
\hline Valencene + geranial & 0.12 & 10.834 \\
\hline Dodecanal & 0.03 & 11.085 \\
\hline$\delta$ cadinene + citronellol & 0.04 & 14.039 \\
\hline Nerol & 0.03 & 14.300 \\
\hline Geraniol & Trace & 14.400 \\
\hline$\beta$ sinensal & Trace & 15.538 \\
\hline$\alpha$ sinensal & 0.03 & 19.796 \\
\hline
\end{tabular}

\section{Discussion}

Twenty-eight volatile compounds were identified in the essential oil extracted from Citrus sinensis epicarp with a predominance of terpene compounds (50\%), aldehydes (32\%) and alcohols (18\%). Hydrocarbon monoterpenes limonene (94.4\%) and the association of phellandrene and myrcene $(1.92 \%)$ were the major compounds.

The extraction yield was $0.0007 \%$. This is insignificant compared to the range of $0.2 \%-2 \%$, to which the yield of a good extraction of essential oil should belong [4]. This low yield could be associated with the extraction technique, including the water steam distillation. Moreover, the defaults on the locally manufactured apparatus contribute to the loss of steam during the distillation process. After investigating previous work on essential oils from Citrus genus, it is clear that limonene is provided with anti-inflammatory properties. Indeed, limonene reduces the production of pro-inflammatory cytokine (TNF-alpha) and nitrate oxide regulator of inflammation by inhibiting the activity of polysaccharides that stimulate excessive production. So limonene looks like an effective anti-inflammatory, especially in the case of inflammation of skin $[5,6]$.

Overall, monoterpenes have several therapeutic properties, especially insecticidal and antidiabetic 
properties. It turned out that the monoterpenes from the essential oil of Citrus sinensis epicarp have larvicidal activity against larvae of the mosquito-Aedes aegypti that causes yellow fever [7] in the fourth larval stage Culex pipiens $[8,9]$. In the case of diabetes type 1 called insulin dependent diabetes, monoterpenes have the ability to mimic the properties of insulin, induce the secretion of the latter by regenerating dead pancreatic beta cells, or in further stimulate their secretion by alive pancreatic beta cells $[10,11]$.

The antioxidant activity of the essential oil of Citrus sinensis epicarp has recently been highlighted and it was attributed to the presence of phenolic compound [12].

\section{Conclusions}

At the end of this work, the authors could consider the essential oil of Citrus sinensis epicarp as an environmentally friendly product and so reuse its epicarp as a gainful mean. Indeed, due to its anti-inflammatory and antioxidant properties, it is used in the composition of anti-aging, anti-pain, anti-rheumatism and cosmetic products. Moreover, it could be a good product against insects, since it has larvicidal properties.

\section{References}

[1] Boushia, N. 2013. "Extraction of Essential Oil Rich in Antioxydants from Natural Products and Food Co-products." Normal University of Agronomy of Alger. Accessed December 6, 2013. https://tel.archives-ouvertes.fr/tel-00915117/document.

[2] Lecourtois, A. 2012. "Making of Municipal Solid Waste: A Resource." Accessed October, 2012. http://www.proparco.fr/jahia/webdav/site/proparco/share d/PORTAILS/Secteur_prive_developpement/PDF/SPD15 /SPD15_Tandon_Tranie_fr.pdf. (in French)

[3] Vasuedeva, N., and Sharma, T. 2012. "Chemical Composition and Antimicrobial Activity of Essential Oil of Citrus limettioides Tanaka." Journal of Pharmaceutical Technology and Drug Research 1: 2.

[4] Minh Tu, N. T., Onishi, Y., Choi, H. S., Kondo, Y., Bassore, S. M., Ukeda, H., and Sawamura, M. 2002. "Characteristic Odor Components of Citrus sphaerocarpa Tanaka (Kabosu) Cold-Pressed Peel Oil.” J. Agri. Food Chem. 50 (10): 2908-13.

[5] Hamdan, D. I., Mohamed, M. E., Abdulla, R. H., Mohamed, S. M., and El-Shazly, A. M. 2013. "Anti-inflammatory, Insecticidal and Antimicrobial Activities and Chemical Composition of the Essential Oils of Different Plants Organs from Navel Orange (Citrus sinensis (L.) Osbeck var. Molesy) Grown in Egypt." Journal of Medicinal Plants Research 7 (18): 1204-15.

[6] Yoon, W. J., Lee, N. H., and Hyun, C. G. 2010. "Limonene Suppresses Lipopolysaccharide-Induced Production of Nitric Oxide Prostaglandin $E_{2}$ and Pro-inflammatory Cytokines in RAW 264.7 Macrophages." J. Oleo Sci. 59 (8): 415-21.

[7] Amusan, A. A., Idowu, A. B., and Arowolo, F. S. 2005. "Comparative Toxicity Effect of Bush Tea Leaves (Hyptis suaveolens) and Orange Peel (Citrus sinensis) Oil Extract on Larval of the Yellow Fever Mosquito Aedes aegypti." Tanz. Health Res Bull. 7 (3): 174-8.

[8] Shalaby, A. A., Allam, K. A., Mostafa, A. A., and Fahmy, S. M. 1998. "Insecticidal Properties of Citrus Oil against Culex pipiens and Musca domestica." J. Egyptian Soc. Parasitol. 28 (2): 595-606.

[9] Zahran, H. E. D. M., and Abdelgaleil, S. A. M. 2010. Insecticidal and Developmental Inhibitory Properties of Monoterpenes on Culex pipiens L. (Diptera: Culicidae).” J. Asia-Pacific Entomol. 14 (1): 46-51.

[10] Tavafi, M., Ahmadvand, H., Tamjidipoor, A., Delfanc, B., and Khalatbarid, A. R. 2011. "Satureja khozestanica Essential Oil Ameliorates Progression of Diabetic Nephropathy in Uninephrectomized Diabetic Rats." Tissue and Cell Journal 43 (1): 45-51.

[11] Muhammad, N. O., Soji-Omoniwa, O., Usman, L. A., and Omoniwa, B. P. 2013. "Antihyperglycemic Activity of Leaf Essential Oil of Citrus sinensis (L.) Osbeck on Alloxan Induced Diabetic Rats." Annual Review and Research in Biology 3 (4): 825-34.

[12] Ghulam-Kamal, M., Yasinashraf, M., Izazhussain, A., Shahzadi, A., and Chughtai, M. I. 2013. "Antioxidant Potential of Peel Essential Oils of Three Pakistani Citrus Species: Citrus reticulata, Citrus sinensis and Citrus paradisii.” Pak. J. Bot. 45 (4): 1449-54. 